J. Egypt. Soc. Parasitol. (JESP), 51(2), 2021: 323 - 331

(Online: 2090-2549)

\title{
EFFECT OF INTRA LUMINAL SHUNTS IN OFF PUMP CORONARY BY PASS GRAFTING ON LONG TERM GRAFT PATENCY BY
}

\author{
ASHRAF M. ELBASSIONY ${ }^{{ }^{*}}$ and SAMER ABDELSHAFY \\ Consultant Cardiothoracic Surgery ${ }^{1}$, Military Medical Academy, Cairo, $11291^{1}$, Egypt \\ ( ${ }^{*}$ Correspondence: abassiony@hotmail.com)
}

\begin{abstract}
The intraluminal coronary shunts (ILS) in OPCAB allow easier, safer, more accurate anastomosis and better myocardial protection by maintaining distal coronary perfusion during beating heart coronary revascularization. This was retrospectively study on sixty patients at Maadi Military Medical Campus who had OPCAB using ILS; Multislice CT and coronary angiography were performed after one year of surgery to assess the graft patency. The total number of grafts was 118, 60 were LIMA (50.8\%) and 58 were SVG (49.2\%). Post operatively seven patients $(11.7 \%)$ had MI, two patients (3.3\%) had wound infection, one patient $(1.7 \%)$ had prolonged ventilation $>24$ hours, and one patient (1.7) had perioperative intra- aortic balloon pump.

By coronary angiography; $102 / 118$ grafts $(86.4 \%)$ were patent, 6 had significant stenosis $(>50 \%)$ and 10 grafts $(8.5 \%)$ were totally occluded. BY CT angiography; 101-grafts $(85.6 \%)$ were patent, 7 -grafts $(5.9 \%)$ had significant stenosis and 10 -grafts $(8.5 \%)$ were totally occluded, but without significant difference between results of coronary angiography, and CT angiography ( $\mathrm{p}>0.05)$.

The results by using ILS during OPCAB was safe and showed very much accepted graft patency one year after OPCAB compared to the studies looked for graft patency after OPCAB but using different methods to achieve bloodless field during anastomosis like snaring and bulldogs, CT angiography is a good modality in terms of follow up after CABG it was a noninvasive technique needs no hospital admission, short examination time and it has high sensitivity and specificity.
\end{abstract}

Key words: Egypt, Patients, Coronary, Intra luminal shunts, Heart coronary revascularization.

\section{Introduction}

Clinical or subclinical manifestations of coronary ischemia may occur when the target vessel is temporarily occluded during revascularization of the beating unsupported heart (Urman and Philip, 2014). In selected cases coronary grafts can be safely constructed on the beating heart without ischemia using a simple and inexpensive intraluminal shunt. The device is easily inserted and removed without damage to the native coronary (Rivetti and Gandra, 1998).

This study aimed to assess effect of intra luminal shunts in off pump coronary on sixty patients at Maadi Military Medical Campus

\section{Subjects and Method}

This retrospective study enrolled 60 patients with multi-vessel coronary artery disease who were scheduled for elective off pump CABG, patient with recent $\mathrm{Mi}$, previous
CABG, concomitant valve lesion, and poor targets were excluded. Patients were subjected to full medical history taking, general and local examinations, ECG, ECHO CT angiography and coronary angiography.

Ethics approval and patients consent: All procedures performed were in accordance with ethical standards of Maadi Military Medical Campus Research Committee and with the 1964 Helsinki declaration, and its later amendments. An informed written consent was obtained from all patients

Surgical procedures: The patients were operated by one surgeon, all procedure were performed via median sternotomy. A stabilizer (octopus III Medtronic INC) was used during anastomosis. Sequence of grafting was always the LAD, PDA and then OM. After coronary arteriotomy suitable size ILS was inserted under direct vision, distal coronary anastomosis was performed using 7-0 
polypropylene however proximal anastomosis to the ascending aorta performed with 60 polypropylene.

All patients were subjected to coronary angiography \& CT angiograph after a year. The study was retrospective clinical trial conducted to find out the effect of ILS in graft patency in patients scheduled for elective OPCAB. Patients were $56(93.3 \%)$ males \& $4(6.7 \%)$ females, with aged ranged between 36 to 67 years with a mean \pm 54 . .

\section{Results}

The details were given in tables $(1,2,3$ \& 4 ) and figures $(1,2,3,4,5,6 \& 7)$.

Table 1: General and clinical characteristics of patients $(\mathrm{n}=60)$
\begin{tabular}{|l|c|}
\hline Parameter & Total no $=60$ \\
\hline Mean age(mean \pm SD) & $54.1 \pm 9.5$ \\
\hline Male & $56(93.3 \%)$ \\
female & $4(6.7 \%)$ \\
\hline Mean Heart rate & $68.9 \pm 7.7$ \\
\hline Mean Systolic BP & $127.5 \pm 8.6$ \\
Mean Diastolic BP & $83.4 \pm 9.6$ \\
\hline Mean Height in cm & $172.5 \pm 9.6$ \\
Mean weight in kg & $83.6 \pm 9.2$ \\
\hline Risk factors for CAD & $36(60 \%)$ \\
\hline Hypertension & $28(46.7 \%)$ \\
\hline Diabetes & $31(51.7 \%)$ \\
\hline Dyslipidaemia & $14(23.3 \%)$ \\
\hline Positive family history & $33(55 \%)$ \\
\hline Obesity & $40(66.7 \%)$ \\
\hline smoking & $14(23.3 \%)$ \\
\hline ECG findings & $12(20 \%)$ \\
\hline Anteroseptal MI & $6(10 \%)$ \\
\hline Inferior MI & $19(31.6 \%)$ \\
\hline LBBB
\end{tabular}

Table 2: Operative and perioperative details

\begin{tabular}{|c|c|c|}
\hline Mean number of grafts & $(\mathrm{M} \pm \mathrm{SD})$ & $1.96 \pm 0.61$ \\
\hline $\begin{array}{l}\text { 1- graft } \\
\text { 2-grafts } \\
\text { 3-grafts }\end{array}$ & & $\begin{array}{l}11(18.3 \%) \\
40(66.7 \%) \\
9(15 \%)\end{array}$ \\
\hline \multicolumn{3}{|l|}{ Type of conduit } \\
\hline $\begin{array}{l}\text { LIMA } \\
\text { SVG }\end{array}$ & & $\begin{array}{l}60(50.8 \%) \\
58(49.2)\end{array}$ \\
\hline $\begin{array}{l}\text { Duration of operation } \\
\text { (minutes) }\end{array}$ & $(\mathrm{M} \pm \mathrm{SD})$ & $215.8 \pm 40.0$ \\
\hline Post-operative bleeding $(\mathrm{ml})$ & $(\mathrm{M} \pm \mathrm{SD})$ & $635.9 \pm 484.7$ \\
\hline $\begin{array}{l}\text { Post-operative mechanical } \\
\text { ventilation (hours) }\end{array}$ & $(\mathrm{M} \pm \mathrm{SD})$ & $7.8 \pm 6.7$ \\
\hline ICU stay (days) & $(\mathrm{M} \pm \mathrm{SD})$ & $2.4 \pm 3.1$ \\
\hline Hospital stay (days) & $(\mathrm{M} \pm \mathrm{SD})$ & $7.36 \pm 1.1$ \\
\hline
\end{tabular}

Table 3: Post-operative complications

\begin{tabular}{|l|l|}
\hline Parameter & Number \& \% \\
\hline wound infection & $2(3.3 \%)$ \\
Infarction & $7(11.7 \%)$ \\
Intra-aortic balloon & $1(1.7 \%)$ \\
prolonged ventilation $>24$ hours & $1(1.7 \%)$ \\
\hline Arrythmia: & \\
Atrial fibrillation & $15(25 \%)$ \\
Ventricular tachycardia & $7(11.7 \%)$ \\
Heart Block & $1(1.7 \%)$ \\
Frequent PVCs & $33(55 \%)$ \\
\hline
\end{tabular}

Grafts means were $1.9 \pm 0.61$ distributed as $11(18.3 \%)$ patients, 1 had graft, 40 (66.7\%) patients had 2 grafts \& 9(15\%) pa- tients had 3grafts. Total number of grafts was 118,60 grafts $(50.8 \%)$ were LIMA and 58 grafts $(49.2 \%)$ were SVG grafts. Mean 
operation duration was $215.8 \pm 40.0$ minutes, mean post-operative intubation time was $7.8 \pm 6.7$ hours, mean duration of ICU stay was $2.4 \pm 1.5$ days and mean hospital stay was $7.36 \pm 1.1$ day.

Two patient had wound infection, seven patients had myocardial infarction, one patient had insertion of IABP inserted at the induction time of anesthesia and pulled out
24 hours after the operation this patient had critical left main disease with ejection fraction $42 \%, 15$ had atrial fibrillation ventricular tachycardia in seven patients, heart block in one patient required temporary pacing and then recovered after 2 days, frequent PVCs in 33 patients, and one patient had prolonged ventilation, there were no CNS complication in this series.

Table 4: Coronary angiography in comparison to CT angiography

\begin{tabular}{|l|l|l|l|}
\hline Parameter & $\begin{array}{l}\text { coronary angiography } \\
\mathrm{No}=118 \text { grafts }\end{array}$ & $\begin{array}{l}\mathrm{CT} \text { angiography } \\
\mathrm{No}=118 \text { grafts }\end{array}$ & P value \\
\hline patent graft & $102(86.4 \%)$ & $101(85.6 \%)$ & \\
significant stenosis $>50 \%$ & $6(5.1 \%)$ & $7(5.9 \%)$ & $>0.05$ \\
totally occluded & $10(8.5 \%)$ & $10(8.5 \%)$ & \\
\hline LIMA grafts: $\mathrm{N}=60$ & & $55(91.7 \%)$ & \\
Patent & $56(93.3 \%)$ & $2(3.3 \%)$ & $>0.05$ \\
significant stenosis $>50 \%$ & $1(1.7 \%)$ & $3(5 \%)$ & \\
totally occluded & $3(5 \%)$ & $46(79.3 \%)$ & \\
\hline Venous grafts: $\mathrm{N}=58$ & $46(79.3 \%)$ & $5(8.6 \%)$ & $>0.05 \%$ \\
patent & $5(8.6 \%)$ & $7(12.1 \%)$ & \\
significant stenosis $>50 \%$ & $7(12.1 \%)$ & & \\
totally occluded & \multicolumn{2}{|l}{} \\
\hline
\end{tabular}

\section{Discussion}

Technical advances have made the performance of multi-vessel off-pump coronary artery bypass feasible. The snaring and intraluminal shunts are the techniques used for vascular control. The snaring provides a bloodless surgical field, is usually well tolerated by the patient and is supported by many years of experience. Intraluminal shunts aim to achieve hemostasis at the arteriotomy side and to allow antegrade flow to provide myocardial protection. There are unresolved issues regarding whether shunts have a clinical benefit to provide adequate flow to provide myocardial protection and whether they cause significant endothelial damage 4. Our results demonstrated the high accuracy of CT angiography for diagnosis of graft patency after CABG and the accuracy was maximal with SVG because venous bypass grafts are typically larger in diameter than the native epicardial coronary arteries (approximately $4-10 \mathrm{~mm}$ versus $2-5 \mathrm{~mm}$ ), and they are less subjected to cardiac motion. Accordingly, even with older generation (non-cardiac $\mathrm{Ct}$ machines, investigators examined contrast enhancement along the course of the graft to establish bypass patency. Along with the technical developments, the accuracy reported with this approach increased. However, due to the inherent limitations of non-gated scanning with relatively long acquisition times, overall diagnostic accuracy regarding bypass graft patency remained at approximately $90 \%$, with better results for(larger) vein grafts than for the arterial grafts. it was not possible to identify potential non occlusive high grade bypass body stenosis, the distal anastomosis of the grafts or the native coronary artery run-off 8 . In terms of graft patency, the present results showed $93.3 \%$ \& $79.3 \%$ of the LIMA and SVG respectively were patent after one year, which more or less agreed with other authors abroad.

The very first direct coronary revascularization procedures in the early 1960s were performed on the beating heart without CPB (Goetz et al, 1961). Kim et al. (2001) in Korea stated that there was concern that a hypercoagulable status is caused after coronary artery bypass grafting without cardiopulmonary bypass (off-pump coronary artery bypass grafting, or OPCAB) and may poten- 
tially endanger the patency of the anastomosis. They demonstrated that the patency rate of SVG after OPCAB was significantly lower than that of arterial grafts in the early postoperative CAG $(\mathrm{p}<0.001)$, and was also significantly lower than those of SVG of GII $(p<0.001)$ and GIII $(p<0.01)$ in the postoperative 1-year $\mathrm{CAG}$, although there was no significant difference in 1-year patency of arterial grafts among the three groups. The present results suggested that a specific perioperative anticoagulant therapy may be advisable in patients undergoing OPCAB with SVG. They looked at the graft patency in 90 patients by coronary angiography after one year and the results were $97.8 \%(132 / 135)$ and $67.9 \%(106 / 156)$ for arterial and venous conduits respectively.

Koutlas et al. (2000) in USA stated that the beating heart or "off-pump" coronary artery bypass (OP-CAB) has become an accepted method of myocardial revascularization by reducing the perioperative morbidity related to cardiopulmonary bypass (CPB). However, the efficacy of OP-CAB has not been well established in the elderly patient population. Their mean patient age for both groups was $79+/-0.5$ years and preoperative risk factors were similar. There were no differences in postoperative myocardial infarction, atrial fibrillation, bleeding, neurologic complications, or renal failure. There were no deaths after OP-CAB, compared with the $7.6 \%$ operative mortality rate after $\mathrm{CABG}$ $(\mathrm{p}<0.05)$. The OP-CAB group had a significantly shorter postoperative length of stay $(4.4+/-0.4$ days vs. $8.4+/-0.6$ days $)$ and lower transfusion requirements $(0.4+/-0.1$ units packed red blood cells vs. $1.9+/-0.2$ units packed red blood cells) than the CABG group. They demonstrated that $\mathrm{OP}-\mathrm{CAB}$ is a safe and efficacious method of myocardial revascularization in the elderly, and may actually be preferential in these patients when applicable.

Yeatman et al. (2002) in the United Kingdom investigated the hemodynamic changes in patients undergoing multiple vessels beat- ing heart coronary revascularization in the presence or absence of an intracoronary shunt. They reported that the stabilization of the left anterior descending coronary artery to perform the anastomosis resulted in temporary hemodynamic changes, which are prevented by the use of an intracoronary shunt. The hemodynamic deterioration during the construction of the posterior descending coronary artery and circumflex coronary artery anastomoses is transient in the shunt group, whereas the snaring technique is associated with an impairment of early functional recovery.

Tello et al. (2002) in USA reported that a four-point ordinal-scale qualitative flow index was used for assessment of patency of 75 coronary artery bypass grafts in 26 patients examined with spiral computed tomography (CT). CT findings were compared with selective graft angiographic findings. Of 54 open grafts, 52 were patent at initial selective graft angiography and 50 were patent at spiral CT; accuracy rates were $97 \%$ (73 of 75) and 95\% (71 of 75), respectively. Spiral CT flow index agreed with angiographically determined flow in 85\% (95\% CI: $0.77,0.93)$ of grafts. The kappa statistic demonstrated best to excellent intermodality (0.75) and interobserver (0.89) agreement. Spiral CT may be a feasible means of assessing quality of flow in bypass grafts.

Demaria et al. (2003) in Canada reported that the insertion of intracoronary shunts during off-pump coronary artery bypass surgery can induce a severe endothelial dysfunction. The purpose of this study was to propose a new intracoronary shunt design called Monoshunt, to avoid distal endothelial damage of the target artery in a porcine model. The use of the Monoshunt avoids distal endothelial denudation and allows distal coronary perfusion.

Widimsky et al. (2004) in Czech Republic reported that arterial and venous conduits patency after one year was $91 \%$ and $49 \%$ respectively. They concluded that patency of arterial coronary bypass grafts done on the 
beating heart is excellent and equal to grafts done on pump. The off-pump procedure in the unselected patient population results in fewer patent saphenous grafts per patient.

Dewey et al. (2004) in Germany reported that the computed tomography (CT) with four detector rows and magnetic resonance imaging (MRI) are still of limited value for the assessment of coronary artery bypass grafts (CABG). We investigated the abilities of 16-slice CT in these patients. They concluded that MSCT angiography with 16 detector rows and an isotropic high resolution reliably depicts $\mathrm{CABG}$ with adequate diagnostic quality.

Di Lazzaro et al. (2006) in Italy used computed tomography to study all patients with a radial artery graft operated on in 2002. The scans revealed a $97.77 \%$ (44 of 45) patency rate for left internal mammary arteries, $90.57 \%$ (48 of 53) for vein grafts, and $73.91 \%$ (34 of 46 ) for radial arteries (mammary artery plus vein grafts versus radial artery patency, $p<0.001)$. If analyzed for target vessel, we found the poorest result of radial grafts when placed on the right coronary artery (40\% [2 of 5] patency rate). They concluded that the noninvasive control of previously bypassed patients is feasible, with no discomfort for them and excellent visualization of grafts. The use of the radial artery as a conduit for bypass graft can be achieved with good results, after a careful choice of the target vessel.

Cho et al. (2007) in Korea studied the post-operative one year results after offpump CABG in 833 patients by coronary angiography and they found $95.1 \%$ and $78.8 \%$ patency in arterial and venous conduits respectively. They concluded that their results revealed that saphenous vein graft use in OPCAB independently predicted the graft failure while increasing the target vessel revascularization rate during the first postoperative year. Exclusive arterial revascularization would be a preferable strategy in OPCAB.

Parissis et al. (2014) in England reported that although the literature has failed to project an overall superiority of off-pump vs. on-pump surgery, nevertheless, small randomized control trials and large metaanalysis studies have concluded that the incidence of a stroke is less than $1 \%$ when anaortic off-pump techniques are advocated in patients with diseased ascending aorta. Furthermore, off-pump techniques or their combination with hybrid procedures may lead to a reduction of adverse outcome in the aged high-risk population with concomitant poor left ventricular function and the co-morbidities. However, despite this, controversy still exists among the cardiac surgery community in terms of the benefit of this technique and its safety; hence, off-pump is becoming out of fashion.

Gaudino et al. (2018) concluded that more than 30 years after the introduction of OP$\mathrm{CAB}$, its role in coronary surgery remains debated. In the general population, OPCAB has been associated with similar short-term outcomes, at least when performed by experienced surgeons. In the long term, inferior outcomes have been reported with OPCAB. High-risk patients can potentially benefit from $\mathrm{OPCAB}$, and this seems to be particularly relevant for patients at high risk of intraoperative stroke who are operated with the anaortic technique, but this hypothesis has not been adequately tested in randomized studies. The use of minimally invasive and hybrid approaches is promising.

\section{Conclusion}

The using intra-luminal shunt during offpump coronary artery bypass surgery is safe; it provides a relatively bloodless field; the forward flow in the shunt helps to prevent ischaemia, it facilitates the construction of the anastomosis by protecting the back wall of the artery; traction on the shunt exposes the edges of the areteriotomy and it facilitates training of surgeons to perform offpump technique safely. There data suggested that the use of ILS was associated with mechanical endothelial injury however, this is not unique to the ILS, any contact with the 
endothelium can cause damage, this may occur with snaring, use of blower, application of bulldog clamps, probes, coronary stents and angioplasty, however, there are no data available regarding the effect of ILS usage on graft patency.

Consequently, the multislice CT angiography proved to be a good modality in terms of follow up after coronary artery bypass surgery, non-invasive, with a short examination time, needs no hospital admission with high sensitivity and specificity.

\section{References}

Cho, KR, Jeong, DS, Kim, KB, 2007: Influence of vein graft use on postoperative 1-year results after off-pump coronary artery bypass surgery. Eur. J. Cardiothoracic Surg. 32:718-23

Demaria, RG, Malo, O, Carrier, M, Perrault, LP, 2003: The monoshunt: A new intracoronary shunt design to avoid distal endothelial dysfunction during off-pump coronary artery bypass. Interactive Cardiovascul. Thorac. Surg. 2:281-6.

Dewey, M, Lembcke, A, Enzweiler, C, Hamm, B, Rogalla, P, 2004: Coronary artery bypass graft flow: Qualitative evaluation with cine single detector row CT and comparison with findings at angiography Radiology 224:913-8.

Di Lazzaro, D, Ragni, T, Di Manici, G, Bardelli, G, Da Col, U, et al, 2006: Noninvasive Midrem follow up of radial artery bypass grafts with 16 slice computed tomography. Ann. Thorac. Surg. 82:44-50.

Gaudino, M, Angelini, GD, Antoniades, C, Bakaeen, F, Benedetto, U, et al, 2018: Offpump coronary artery bypass grafting: 30 years of debate. J. Am. Heart Assoc. 7, 16:e009934. doi: 10.1161/ JAHA.118.009934.
Goetz, RH, Rohman, M, Haller, JD, Dee, R, Rosenak, SS, 1961: Internal mammary-coronary artery anastomosis. A nonsuture method employing tantalum rings. J. Thorac. Cardiovasc. Surg. 41:378-86.

Kim, KB, Lim, C, Lee, C, Chae, IH, Oh, BH, et al, 2001: Off-pump coronary artery bypass may decrease the patency of saphenous vein grafts. Ann. Thorac. Surg. 72, 3:S10337

Koutlas, TC, Elbeery, JR, Williams, JM, Moran, JF, Francalancia, NA, et al, 2000: Myocardial re-vascularization in the elderly using beating heart coronary artery bypass surgery. Ann. Thorac. Surg. 10:42-7.

Parissis, H, Ramesh, BC, Al-Alao, B, 2014: Off-pump coronary surgery: current justifications. Gen. Thorac. Cardiovasc. Surg. 62, 11:660-70.

Rivetti, LA, Gandra, SM, 1998: An intraluminal shunt for off-pump coronary artery bypass grafting: Report of 501 consecutive cases and review of the technique. Heart Surg. Forum 1, $1: 30-6$.

Urman, RD, Philip, BK, 2014: Accreditation of ambulatory facilities. Anesthesiol. Clin. 32, 2:551-7

Widimsky, P, Straka, Z, Stros, P, et al, 2004: One year coronary bypass graft patency a randomized comparison between off-pump and onpump surgery angiographic results of the PRAGUE-4 trial. Circulation 110:3418-23.

Yeatman, M, Caputo, M, Narayan, P, Ghosh, AK, Ascione, R, et al, 2002: Intracoronary shunts re- duce transient intraoperative myocardial dysfunction during off-pump coronary operations Ann. Thor-ac. Surg. 73:1411-7.

Fig. 1: Patent LIMA-LAD

Explanation of figures

Fig. 2: Patent LIMA-LAD and SVG - OM

Fig. 3: Patent LIMA and Vein grafts.

Fig. 4: Stenotic LIMA -LAD (arrow).

Fig. 5: Patent LIMA -LAD, SVG-OM.

Fig. 6: Stenotic vein, occluded LIMA.

Fig. 7: Patent LIMA, occluded vein gra1 


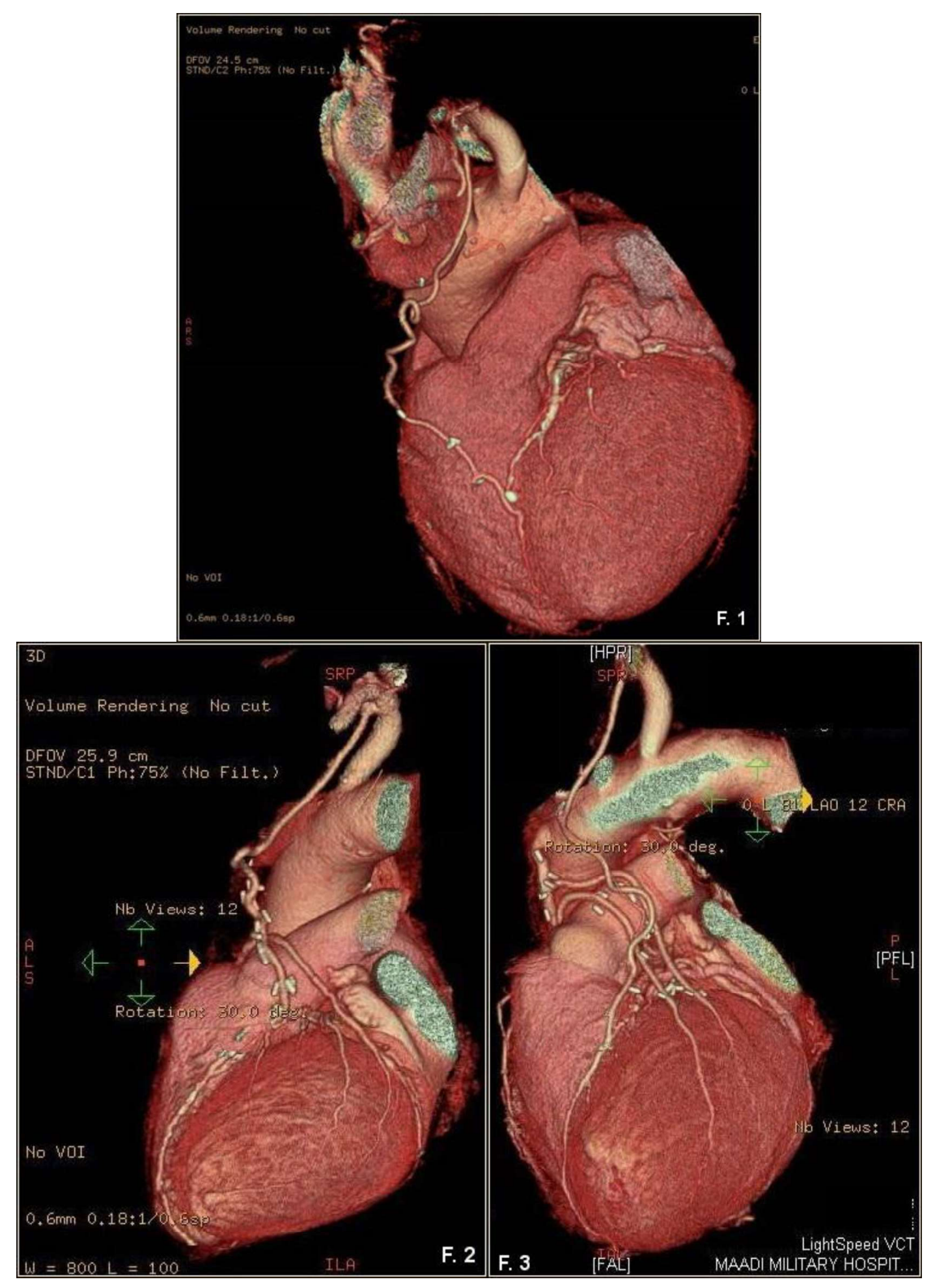




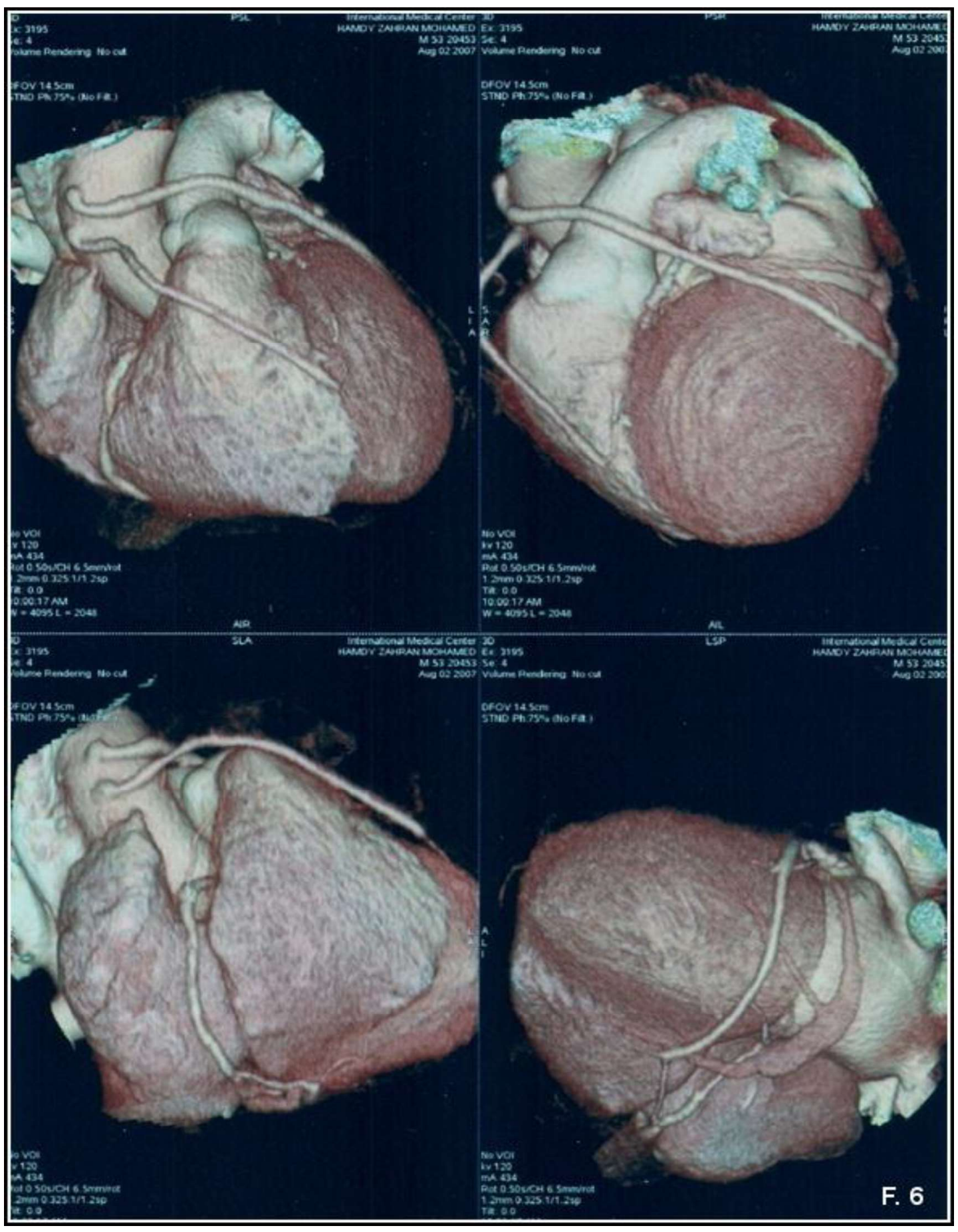



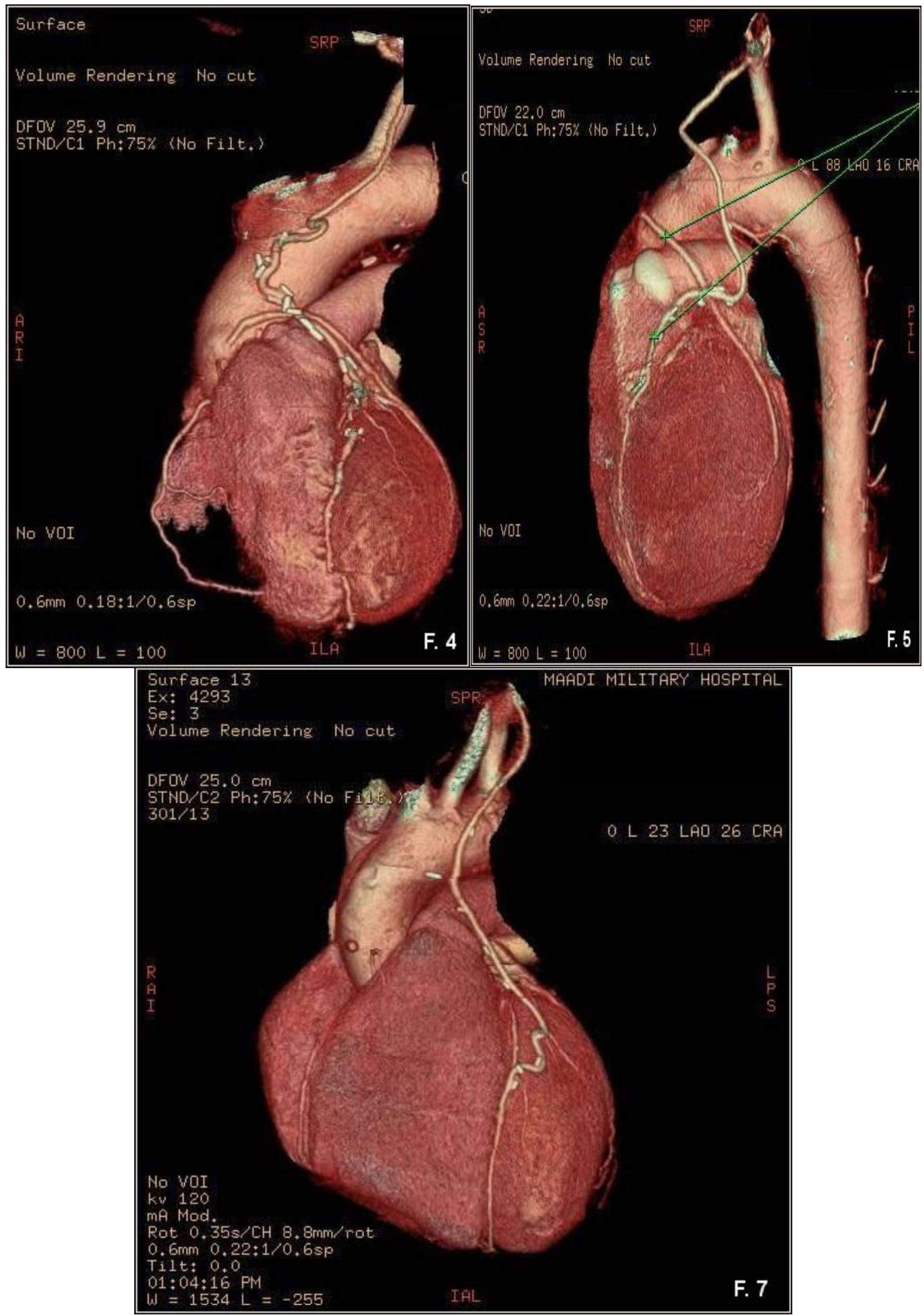